\title{
Energy consumption assessment due to the mobility of inhabitants and multiannual prospective on the horizon 2030-2050 in one Belgium city
}

\author{
Modeste Kameni Nematchoua ${ }^{\mathrm{a}, \mathrm{b}, *}$, José A. Orosa ${ }^{\mathrm{c}}$, Sigrid Reiter ${ }^{\mathrm{b}}$ \\ a Beneficiary of an AXA Research Fund Postdoctoral Grant, Research LeadersFellowships, AXA SA 25 Avenue Matignon 75008 Paris, France \\ ${ }^{\mathrm{b}}$ Local Environment Management \&Analysis (LEMA), Allée de la Découverte9 (bât. B52), Quartier Polytech 1, B-4000 Liège, Belgium \\ ${ }^{c}$ Department of Energy and M. P. EscuelaTécnica Superior de N. y M, University of A Coruña, Paseo de Ronda 51, 15011 A Coruña, Spain
}

\section{A R T I C L E I N F O}

\section{Article history:}

Received 10 November 2018

Received in revised form

5 January 2019

Accepted 8 January 2019

Available online 11 January 2019

\section{Keywords:}

Mobility

Inhabitants

Prospective

Energy consumption

Belgium

\begin{abstract}
A B S T R A C T
In the context of sustainable development, the environmental aspects of urban areas are taken into account by correlating them with their energy consumption. The purpose of this research is to collect and analyze the energy consumption data due to the transport in Belgium, and more precisely in the Liege province. But, also to make forecasts of these same consumptions to the horizon 2030-2050. The methodology chosen allow to model and improve the energy consumption for city-wide transports and to forecast the evolution of city energy consumption to simulate the effects of certain urban development strategies. We focus here on the city of Liege which we will compare the different data of energy consumption with those of other cities. The analysis of the impacts of mobility on energy consumption and greenhouse gas was based on seven scenarios established through several surveys and researches. The results showed that the daily mobility of inhabitants has a significant effect on $\mathrm{CO}_{2}$ emission and energy consumption. It is necessary to act in the long term by encouraging public transport such as vehicles with low energy consumption. The energy consumption in transportation sector can decrease up-to $19 \%$, by reducing between $10 \%$ and $20 \%$, of displacement by private car, and an increase up to $60 \%$, both combined displacement by bike (for the distances small than $12 \mathrm{~km}$ ), and walking (distances small than $1 \mathrm{~km}$ ).
\end{abstract}

(c) 2019 Elsevier Ltd. All rights reserved.

\section{Introduction}

A good energy policy can therefore facilitate the rapid development of a country [1]. Environmental sustainability is the challenge for future long-term success. Today, the transition between renewable and fossil energy is extremely slow, despite several state summits summoned for this purpose [2,3]. Thus, each country develops its own energy policy by ensuring the availability of energy resources in sufficient quantities corresponding to the needs of its users in terms of quality, efficiency and safety.

Politicians and leaders of poor and emerging countries are slow to develop good energy policies in their countries. As a result, it is difficult to install energy-intensive industries in these countries. For specialists in development, energy consumption is an indicator of the level of development in the dynamism of economy of a

\footnotetext{
* Corresponding author.

E-mail address: kameni.modeste@yahoo.fr (M.K. Nematchoua).
}

country [4-6].

According to IPCC [7], one of the main causes of global warming is the emission of greenhouse gases due to energy production. Globally, it has been shown that the transport sector accounts for about $30 \%$ of total energy use [10]. As shown in several studies, transport indicates one of the most active areas of the economy in terms of energy use and the spread of greenhouse gases in all countries [11,12]. It was agreed that vehicle use and economic growth were linked to energy growth from transport and GHG emissions [13]. Until now, the tests did not reflect the reality of consumption under actual conditions of use. The European Transport and Environment Association has agreed on a measurement protocol much closer to reality [15]. To be more efficient, this consumption should integrate the gray energy, ie the energy consumed throughout the life cycle of the vehicle, from manufacture to recycling, not to forget the transport infrastructure, whether road or rail [16]. Mobility in urban areas represents an important part of consumption energy sector. Indeed, developing countries are urbanizing faster than they are industrializing. This 
urbanization does not follow the path drawn by the northern countries [18]. The development of the automobile has led to a very sharp drop of the urban population density in Western countries [19].

Nowadays, the transport policies in regions with an important economic growth have several impacts than in industrialized regions. For example in its new policy, China agreed limit the rate of GHG emission encouraging gas car and fuel economy standard in several cities [8]. According to Julien Allaire [20], the rate of greenhouse gas emissions and energy consumption have steadily increased. Between 1990 and 2007, global $\mathrm{CO}_{2}$ emissions from transport increased by $45 \%$. This trend is particularly noticeable in developing countries and emerging economies. $\mathrm{CO}_{2}$ emissions from transport increased sharply between 1990 and 2009, so that for all non-industrialized countries these emissions accounted for almost $7 \%$ in 1990 and jumped to nearly $14 \%$ in 2009 [21]. The adoption of these methods should bring a decrease of energy consumption till more than of uncontrolled scenario [9]. The utilization of petroleum as a fuel for transport decrease with adaption of renewable energy. For example in Belgium, the energy sector was one of the drivers of economic development in the 19th century. Nevertheless, since this time Belgium is totally staying dependent on foreign countries for its oil, natural gas and coal needs, which account for $72.4 \%$ of its primary energy consumption in 2014 (42.3\%, 23\% and 23\%,respectively) [14]. Final energy consumption was split in 2014 mainly between industry (26.6\%), transport (21.7\%), residential (18.4\%) and tertiary (10.6\%). Moreover, Belgium's energy-related $\mathrm{CO}_{2}$ emissions in 2015 amounted to 8.25 tonnes of $\mathrm{CO}_{2}$ per capita, $87 \%$ higher than the world average, and $89 \%$ this of France, but, inferior to $8 \%$ at this of Germany [14]. According to the International Energy Agency [17], in 2004 , road transport accounted for $16 \%$ of $\mathrm{CO}_{2}$ production, but that data rose to more than $26 \%$ in 2010 in most developed countries. According to the World Bank, $\mathrm{CO}_{2}$ emissions from transport in Belgium, was estimated at $28.63 \%$ in 2014 .

One of the major objectives of the European Union in its new policy since 1990 is to reduce the production of greenhouse gases by $20 \%$, secondly to promote energy efficiency by $20 \%$, and finally, to produce 20\% energy, from renewable energy sources, by 2020 . Thus was born the slogan "20-20-20 in 2020" [39].

This recent decade, some works studied transport energy consumption. In 2008, Poudenx [22] stated that greenhouse gas emissions and energy use are directly related to different transportation policies, while Ogilvie et al. [23] stated that a sustainable transportation policy should facilitate development of the most energy-efficient modes of transport, such as walking, cycling and public transport. The various policies and structures with the aim of modifying the supply of legislative or physical transport were divided into several classes in 2001 by Fujii et al. [24]. In 2004, Cairns et al. [25] showed that good mobility planning will facilitate instilling a policy of reducing the car journey to less than $3 \mathrm{~km} /$ person each day. This result was confirmed in 2007 by Parker et al. [26]. Private vehicles consume nearly five times the energy used by public vehicles, thus encouraging the population to adapt to public transport, reduce the demand for energy and $\mathrm{CO}_{2}$ emission [27]. Other researches were showed in Refs. $[28,29]$. Today, seen, to reduce carbon emissions and the depletion of fossil fuels, it is urgent to find a lasting solution. To do this, it is important to know the energy consumption related to the different current sectors. This project aims to establish a methodology and studied the current trends in energy consumption, as well as the prospects. In addition, its goal is to make multi-year seasonal forecasts of energy consumption by 2030-2050 for a given city typology.

This research was constituted of some mains sections. Indeed, Section 2 describes the methodology used. Section 3 presents the results analysis from the research, section 4 presents analysis and discussion, and Section 5 concludes the paper while giving some outlooks.

\section{Methods}

\subsection{Studied city}

Belgium is a federal state comprising three regions: the Walloon Region (Wallonia), the Flemish Region (Flanders) and the Brussels Region (Brussels-Capital). The population is concentrated in the region of Brussels-Capital which occupies a very small part of the territory is $161 \mathrm{~km}^{2}$, which is equivalent to $0.5 \%$ of the area of Belgium. It has, however, a very high population density of about 7057 inhabitants per $\mathrm{km}^{2}$ on 1 January 2012, a density nearly 20 times higher than the national average of around 360 inhabitants per $\mathrm{km}^{2}$. This difference in the distribution of the population was reflected in the typology of the buildings and the type of neighbourhood encountered. Liege is a French-speaking city in Belgium located in the north-east of the country, in Wallonia, a few kilometres from the Dutch and German borders. It is the capital of the province of Liege and the economic capital of Wallonia.

The Liege city is characterized by a continental climate with a hint of oceanic influence. This means that winters are harsh and relatively wet and summers are hot and sunny. Thus, the climate of Liege is particularly favourable for outdoor activities during the five months which include the end of spring, all the summer and the beginning of autumn. In summer, the temperature is close to zero, at the worst times of the day. The beginning of spring is dominated by low temperatures that reflect the freshness of the atmosphere; and the beginning of the summer is quite rainy, with relatively heavy showers in June. The Fig. 1 showed the studied place. This city has 10 sections and 27 neighbourhoods for a little over 600,000 inhabitants in 2010.

\subsection{Weather data and some hypothesis}

The analysis of meteorological data, allowed see, if they have any influence on the choice of mode of transport (example: walking or travelling by bike if the weather is good; driving by car if it rains ...). The following data will be taken into consideration: precipitation, maximum, minimum and average temperatures, sunshine duration and maximum wind speed. All these data were available at the weather station of Liege city.

In this study, (i) it is possible to formalize the urban system in a homogeneous representation with regard to the common properties that bring together the various flows that cross the city; (ii) we

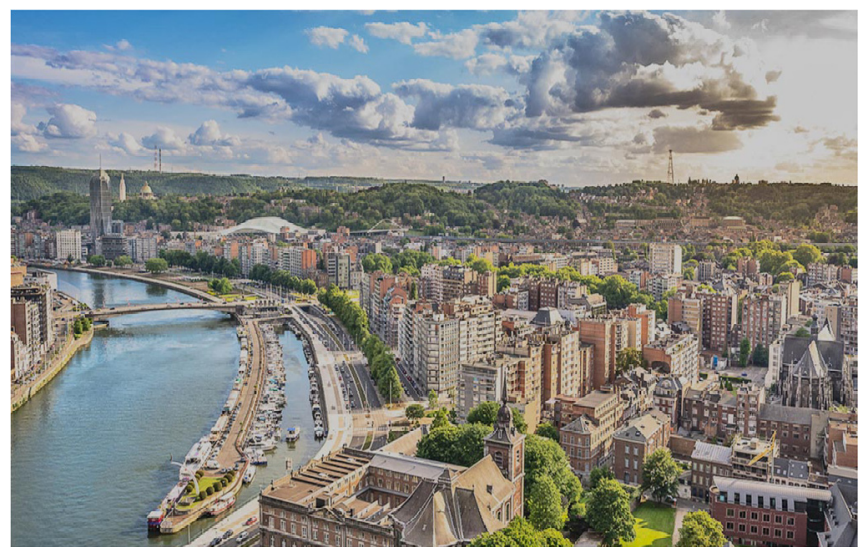

Fig. 1. Studied city. 
will not take into account the soft modes of transport, because they do not consume energy. Motorized two-wheelers will also be neglected because they consume little and are little used, as well as train journeys, which are of little concern to us in the city; (iii) it will be considered that the rate of use of a mode of transport for a given population applies to an individual ( $\mathrm{ex}=$ if the modal share of the bicycle is $5 \%$, it will be considered that an individual will use the bicycle once on 20).

\subsection{Seasonal energy performance index}

The energy performance index (EPI) for (home-work transport), and (home-school transport). It represents the energy used by a person for a home-to-destination trip.

The EPI is calculated as follows:

$E P I_{i}=\sum_{m} \frac{D_{m i} \cdot f_{m}}{T_{i}}$

With the territorial unit (neighbourhood), m: the means of transport used (petrol/diesel car, train, bus, bicycle or on foot),Dmi: the total distance travelled with the means of transport $m$ in district i.

$T_{i}$ : the number of workers/students in the neighbourhood i. $f_{m}$ : consumption factor, 0.61 for a diesel, 0.56 for a petrol and 0.15 for a bus (in $\mathrm{kWh} /$ person).

This index is a good tool to compare the consumption according to travel type.

It could be a great asset for our study, but the available data do not allow calculations for trips other than home-work or homestudy. However, these trips do not cover all the journeys made by a person, and given the distribution of motives for travel, a hypothesis reducing the study to these two grounds would not be justified. In this research, instead of calculating the EPI by reason of displacement, we calculated it by type of day (school/non-school opening, Saturday and Sunday/holidays). The summarize of travelled distance is showed on Table 1.

\subsection{Simulation tools}

We used urban GIS, and statistical processing of transport data to develop a city-wide model. This method combines studies of transport energy consumption and upward and downward approaches (top-down and bottom-up). This makes it possible to obtain data that is as relevant as possible, and to compare different strategies to limit energy consumption in cities.

\subsubsection{Selection of variables}

A wide range of variables is selected to characterize energy efficiency, using the knowledge listed in the literature (cadastral data, energy criteria). These variables are linked to the CCCP(Continuous Cartography Computer Project) by an urban GIS to specialise them in the urban area of Liege.

\subsubsection{Statistical treatment of data}

For data processing, a principal component analysis is used: similar criteria are grouped together to characterize energy performance. In all there are six, we will focus on those related to transport namely: (i) the energy performance index for home-work transport; (ii) the energy performance index for house-school transport.

\subsubsection{Scenarios}

It was noted that between 1991 and 2001, the EPI experienced a $32.3 \%$ increase for the distances home-work, and $8.03 \%$ for homeschool journeys, for a $3 \%$ increase in the number of workers, and $4.3 \%$ as frequency of students over this period. On the basis of these results, we are looking for a transport energy consumption of 3955.3 GWh between home and office, and 187.76 GWh between home and school trips (total of $4140 \mathrm{GWh}$ ) by 2061.

However, thanks to the improved energy performance of vehicles and despite the increased distances travelled, we can assume that in 2030, consumption will be a little greater than in 2005 .

\subsection{Path analysis}

\subsubsection{Case of distance from home to office then between home and} school

The analysis is based on empirical data available at the scale of the building (smaller scale available in Belgium). They come from the national decennial census. This scale also has access to the usual demographic, socio-economic data. It is important to note that this method is specific to the context of the study area. To find the total distance travelled in the year, the number of workers/students is combined with the number of journeys per week (obtained with the number of labour days/school, per year).

\subsubsection{Case of distance from home to shop, then between home and leisure pathways}

For these types of paths, we do not have any data recorded, so we develop a calculation method based on the standard profiles. Studies have established a number of behaviours, which mainly affect distances and frequency of trips. The means of transport were determined according to assumptions based on the distance travelled, the distance to the nearest bus stop and the bus services available. We take into account local shops, suburban shopping centres and city centres.

\subsection{Sensibility}

The factors relevant to improving the energy efficiency of the neighbourhoods studied were identified. Location testing (in terms of distance to downtown and bus service), vehicle performance, commuting distance and a modal choice on overall energy consumption were tested.

Table 1

Travelled distance by Day by Type of Transportation.

\begin{tabular}{|c|c|c|c|c|c|c|c|c|}
\hline & Percentage & $\begin{array}{l}\text { Average travelled distance } \\
\text { (km/year) }\end{array}$ & $\begin{array}{l}\text { Average travelled distance } \\
(\mathrm{km} / \text { day })\end{array}$ & $\begin{array}{l}\text { working } \\
\text { days }\end{array}$ & $\begin{array}{l}\text { school working } \\
\text { days }\end{array}$ & $\begin{array}{l}\text { no-school working } \\
\text { days }\end{array}$ & Saturday & $\begin{array}{l}\text { Sundays and } \\
\text { holidays }\end{array}$ \\
\hline Car & $72 \%$ & 8053.0 & 22.1 & 20.0 & 19.8 & 20,5 & 20.0 & 23.4 \\
\hline Walking & $18 \%$ & 2013.3 & 5.5 & 5.0 & 4.9 & 5.1 & 5.0 & 5.9 \\
\hline Bike & $1 \%$ & 111.8 & 0.3 & 0.3 & 0.3 & 0.3 & 0.3 & 0.3 \\
\hline $\begin{array}{l}\text { Public } \\
\text { transport }\end{array}$ & $8 \%$ & 894.8 & 2.5 & 2.2 & 2.2 & 2.3 & 2.2 & 2.6 \\
\hline various & $1 \%$ & 111.8 & 0.3 & 0.3 & 0.3 & 0.3 & 0.3 & 0.3 \\
\hline Total & $100 \%$ & $11,184.8$ & 30.6 & 27.7 & 27.5 & 28.4 & 27.7 & 32.6 \\
\hline
\end{tabular}




\section{Results}

The analysis of several official reports on demography in Belgium [30-32], as well as the projections for the next 50 years (until 2060) allowed us to draw the Fig. 2.

This figure showed the variation of population from 2010 to 2060. It is seen that, in Belgium, the population will increase up to $10.3 \%$, between 2010 and 2030, then, will increase till $6.2 \%$, (2030-2050), and 2.3\% (2050-2060). While, in Liege, inhabitant percentage will increase to $16.9 \%$ between (2010-2060). Globally in all Wallonia, the population will increase of 18.6\% (2010-2060). Based on some results shown in the BELDAM survey [30], the displacement rate for a given day type will be calculated. The average distance travelled in a day was $13.3 \mathrm{~km}$ (average day), $12 \mathrm{~km}$ (working days), $11.9 \mathrm{~km}$ (school working days), $12.3 \mathrm{~km}$ (noschool working days), $12 \mathrm{~km}$ (Saturdays), and $14.1 \mathrm{~km}$ (Sundays and holidays).

\subsection{Calculation by transportation mode}

Knowing the distance travelled per year and by car, in Wallonia [30], knowing the number of cars and inhabitants in Wallonia [30-32], we obtained the average distance travelled by car per year. With the distribution of the modes of displacement, one obtains the average distance travelled by mode of transport per year, then per day. All that remains is to apply the rates calculated previously, and we obtain the distance travelled by type of day and by mode of transport. As showed the Table 1, it was seen that in Liege everyday day, around $72 \%$ of distance travelled was by car, the $18 \%$ (walking), $8 \%$ (Bus), and only $1 \%$, by bike.

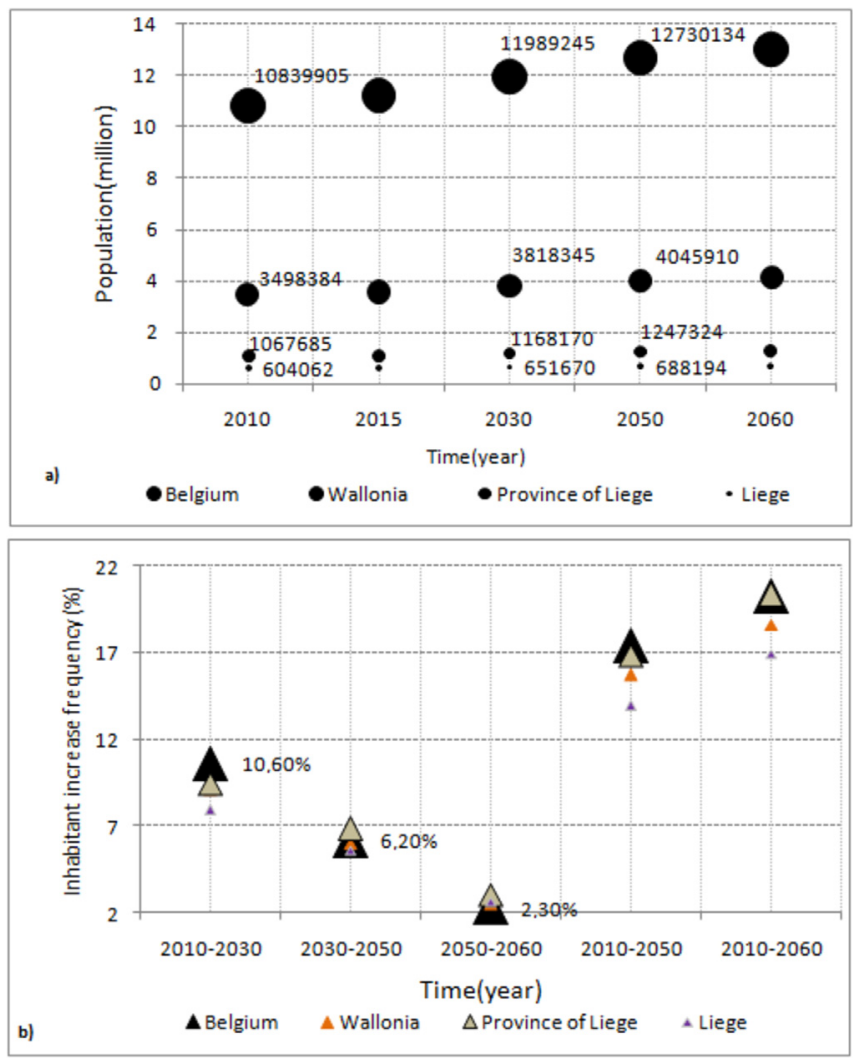

Fig. 2. Inhabitant number between 2010 and 2060(a), and variation of population (b).

\subsection{Energy performance index and consumption}

To evaluate the following index, we considered that $34 \%$ of cars use petrol and 64\% diesel [30]. In Belgium, there are 253 working days, 180 school days and 56 Saturdays [31]. On the Fig. 3, it was showed that the Energy performance index of car with diesel motor is higher than bus and oil car. The consumption factor is the weakest for the public transport (eg; bus).

\subsection{Scenarios analysis}

Under base of the works of Jacques Thiers and ÉricVidalenc [33], it was carried out several Prospects for 2030-2060, and some scenarios were planned. The purpose of this sub section was of assessed the energy consumption coming from transport.

\subsubsection{Passive attendance scenario}

For this first scenario, we consider a very simple case, which could serve as a basis for other scenarios, even if it is very unlikely that it will be realized. Indeed, it is assumed that nothing will be done in the future: no political decision, no technological progress. Thus, the evolution of energy consumption continues linearly, following demographic trends.

We considered a population of 651,670 for Liege for the year 2030 and an evolution of $+17 \%$ of cars per decade [34]. We had made the same calculations of energy performance index and consumptions as in the previous part. The results are shown in Fig. 4: This scenario is unrealistic, but it provides a basis for comparing other scenarios and calculations in a meaningful way: we cannot compare consumption calculated for the year 2030 with the data calculated for the year 2010. We have by 2030 and 2050, the data are showed on Table 2.

\subsubsection{Smart attendance scenario}

This scenario is similar to the first, except that there is still a change in technology, which leads to lower consumption factors [33]. The emphasis is on "no regrets" policies. This will provide benefits in terms of employment, urban attractiveness and poverty reduction.

Long-term decisions are not made because of the uncertainty of the actors of change. Renewable energies are developing slowly. New green technologies (including vehicles) do not find a sufficient market, so they are not very developed. We stress the "no regrets" policies that allow to obtain benefits in terms of employment, urban attractiveness and poverty reduction. No long-term policy is pursued and local policies evolve with changing circumstances and seek both to cushion shocks and to capitalize on opportunities. First, they suffer the counter-effects of a stagnant economy and an explosion of unemployment or social spending. Then, a "window of opportunity" opens, marked by a remobilization on the climatic or energetic questions and a more favourable economic context. We then conduct policies without regret, but it is too late: they do not prevent a new oil shock of much greater magnitude than the previous ones. For having made the choice to avoid rupture, we then face an even more radical break. This is the scenario that seems the closest to a trend.

The event that seems to be most affecting transport is the oil shock of 2035. In order to evaluate its consequences, we based on the evolution of car sales since 2003, since we are facing a major crisis, where the price of gas has quadrupled in 10 years. We will assume that the trend will be the same for the crisis of 2035 .

(i). Consequences of the 2003 oil crisis 


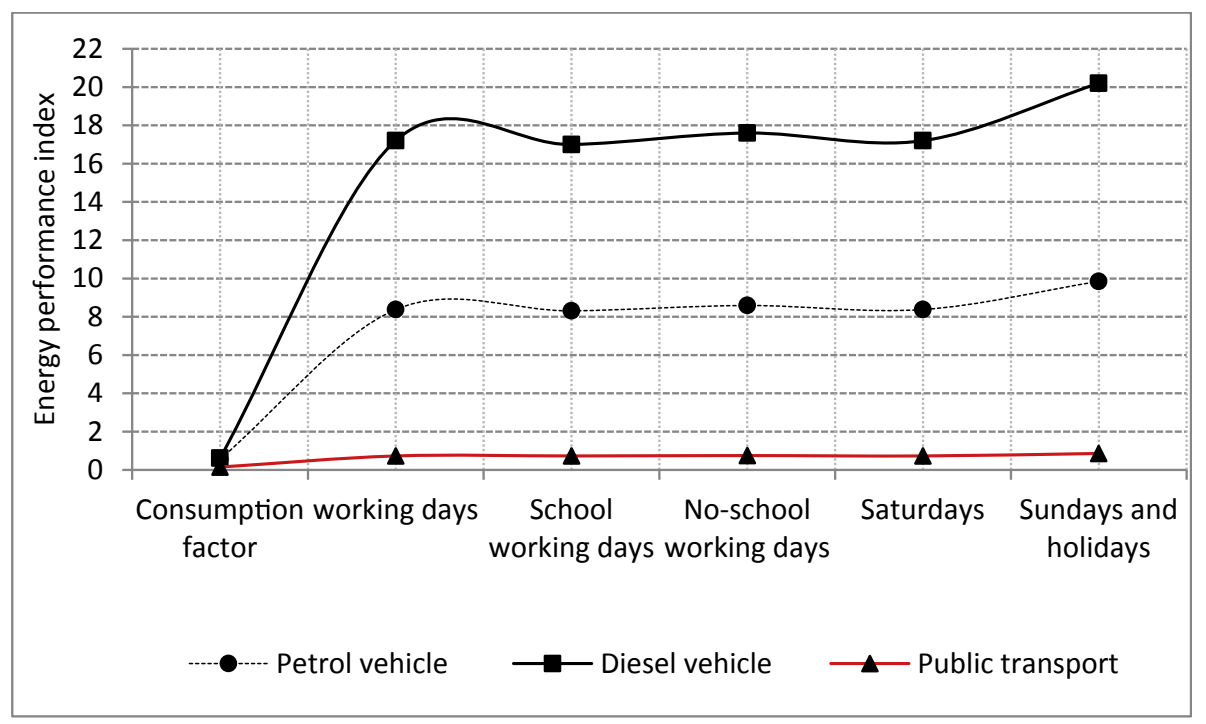

Fig. 3. Energy performance index and consumption by type of transport.

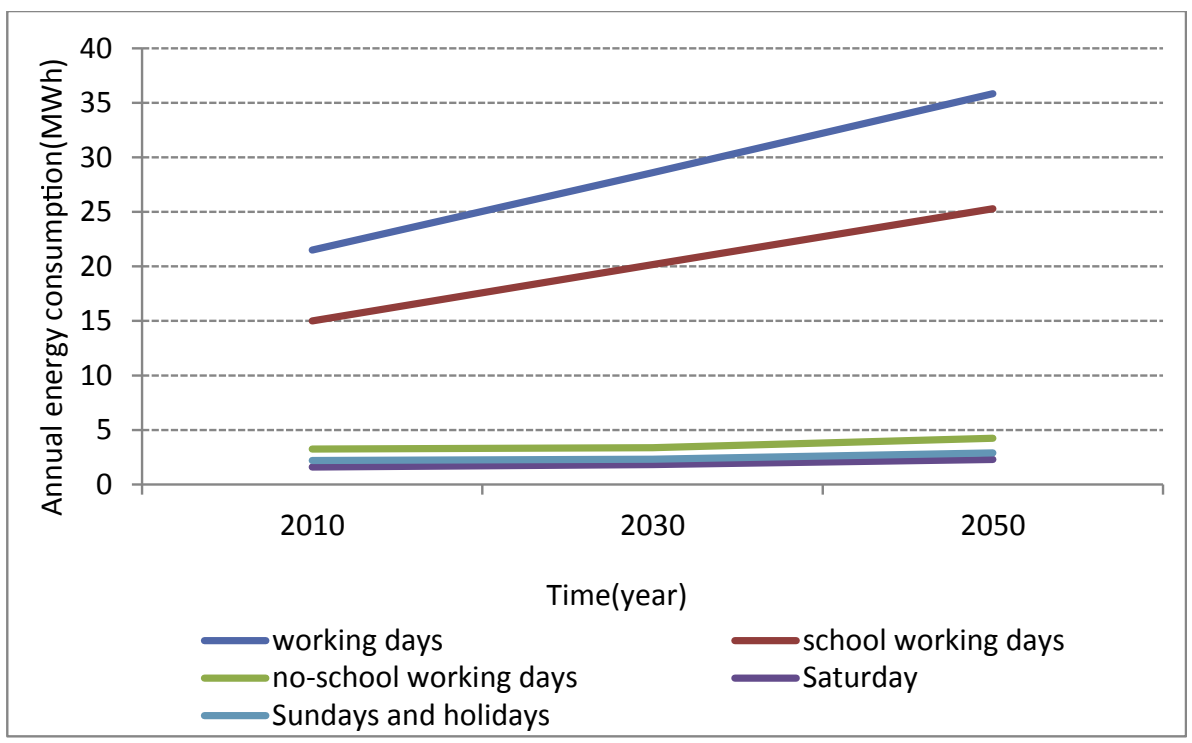

Fig. 4. Energy consumption on three periods (2010, 2030, 2050).

Table 2

Energy consumption in 2030 and 2050 according to the passive attendance scenario.

\begin{tabular}{|c|c|c|c|c|c|}
\hline Energy (kWh) & Working days & School working days & No school working days & Saturday & Sunday and holidays \\
\hline 2030 & 4493.0 & 3170.0 & 531.6 & 287.7 & 363.1 \\
\hline 2050 & 4989.0 & 3520.0 & 590.2 & 319.5 & 403.2 \\
\hline
\end{tabular}

We compared the number of cars registered in Belgium (corresponding to the number of new cars purchased) at the price of a barrel of oil [35], the results are shown in Fig. 5a. We weighted the sales by the number of inhabitants of Belgium (in millions) to be sure that a possible increase would not be the consequence of an increase of population. We note that the entire period of onset of crisis (between 2003 and 2006), sales remain stable despite the increase in the price of a barrel. Then, during the peak of 2008, the car sales fall drastically. In the last part of the graph, the price of oil rises again, the increase in car sales slows and finally relapsed as the price of a barrel stabilizes. This phenomenon can be due to the conception of other car type. For simplicity, we assume that the increase in the price of oil and the fall in car sales occur simultaneously.

\section{(ii). Consequences of the oil shock of 2035}

In 2035, we are facing an oil shock. The barrel of oil reaches $\$$ 250 . It then continues to increase until 2050 to reach $\$ 350$. In order to obtain figures for the prospective sales of cars, we have transcribed the results found in the previous point. For a given increase in the price of oil, we did a thorough analysis of the data and used 


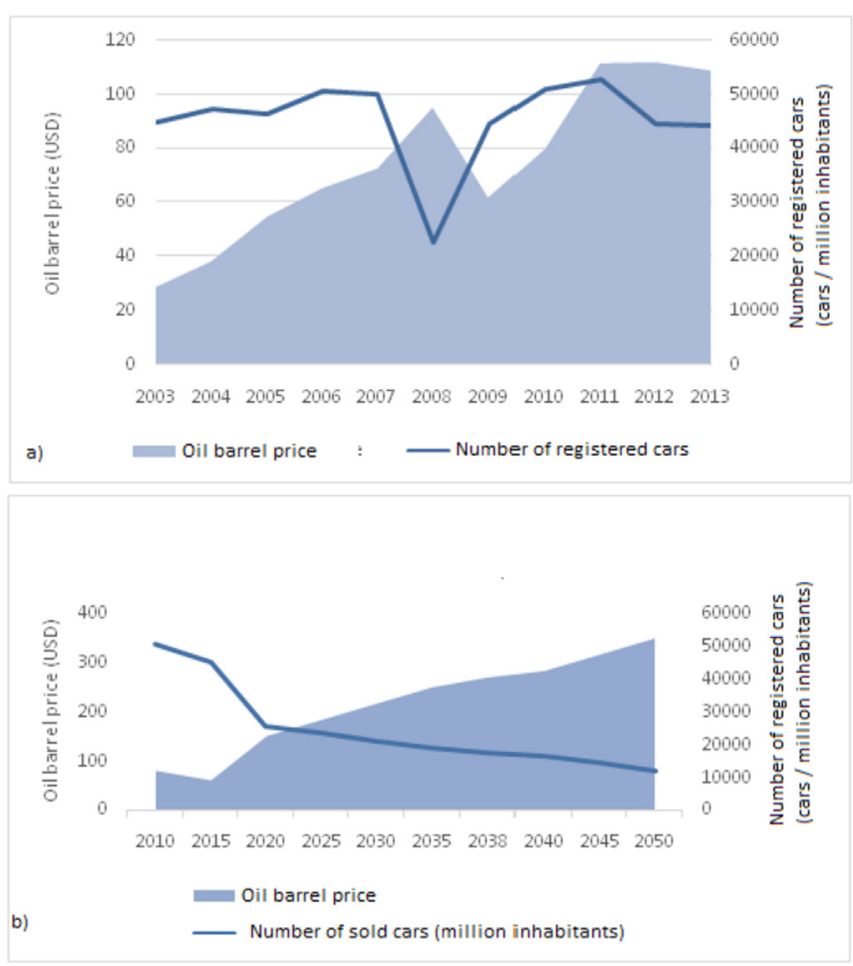

Fig. 5. Oil prices and registrations between 2003 and 2010(a), then between 2010 and 2050(b).

the associated car sales variation (Fig. 5b). There is a massive drop in car registration. Of course, the increase in the price of oil is not the only factor playing on the purchase of cars, there is also (mainly) the economic crisis, playing on the purchasing power of consumers. However, as the economic context is similar to that of 2008 , we considered that this factor is covered by the fact that we are based on the 2008 ratios, where the economic crisis was taken into account.

\section{(iii). Energy performance index (EPI) and consumption in 2030}

In this scenario, we consider that the number of kilometres travelled is the same as in 2010 , ie the number of kilometres travelled per inhabitant has decreased, since the population has increased (651,670 inhabitants in Liege).

At the same time, we considered that technological advances have led to a $5 \%$ increase in the use of electric cars and a $10 \%$ reduction in the energy consumption factors of the various means of transport. Table 3 showed the energy performance index by type of day in 2030, corresponding to this scenario.

Estimating the population of 688,194 inhabitants for Liege [31]. We considered in this scenario that consumption factors are $20 \%$ lower than in 2010 , and that we have a rate of $15 \%$ of electric cars. The energy consumption is shown in Table 4.

The annual energy consumption was expected to be $82.29 \mathrm{kWh}$ (working days), $58.06 \mathrm{kWh}$ (School working days), $9.735 \mathrm{kWh}$ (no school working days), $5.269 \mathrm{kWh}$ (Saturday), and $6.65 \mathrm{kWh}$ (Sunday and holidays); in 2050. Fig. 6a shows the annual consumption according to the Smart Attendance scenario.

It is noticed from this scenario that in the future, the average consumption of vehicles will decrease. We must not forget why there is a fall in consumption: it is not a question here of political choices, but of changes due to the increase in the price of oil. There has been almost no transitional measure, and the country is in a state of serious crisis. In addition, if people use the car less, public transportation becomes saturated.

By analysing these data, it can be concluded that, this scenario seems interesting. At the level of the facts, it is catastrophic, indeed, the consequences of the oil crisis are very serious. But, unfortunately, it was not anticipated.

\subsubsection{Carbon creativity scenario}

Carbon creativity is based on the fact that energy and climate actions can only be effective if we put in place appropriate price or tax signals [33]. It is a scenario of industrial policy, based on the bet that the national companies will be able to benefit from a high carbon price. The engine of the scenario is the interest, in the sense of economic rationality. Cities have less room for maneuver, so they invest in local innovation and set up essential networks (eg the electric car), encourage experimentation and support new services and training for new jobs by multiplying public-private partnerships.

Communities must also be involved in risk management, but they do not all have the same capacity to do so, the inequalities between territories significantly grow.

The choice is made to develop electric and bring the share of electric cars to $40 \%$ in 2050 . The principle of "yield management" is developing in all means of transport. We are in a generalized urban optimization. Tele-working, e-service and teleconferencing are greatly expanded or encouraged.

Some companies go as far as setting up annual travel quotas. This opens up much greater opportunities for homework. We are entering an economy of functionality. In the field of mobility, manufacturers sell their vehicles to private mobility operators who offer monthly packages to their customers. They can then borrow a light electric vehicle and access a wide range of services. This remains, however, reserved for the middle and upper classes of the central cities. In suburban or rural areas, property remains the rule.

Table 3

Energy performance index by type of day in 2030, Smart Attendance.

(iv). EPI and consumption in 2050

\begin{tabular}{|c|c|c|c|c|c|c|c|c|c|c|c|}
\hline & \multicolumn{5}{|c|}{ travelled distance } & \multirow{2}{*}{$\begin{array}{l}\text { Consumption } \\
\text { factor }\end{array}$} & \multicolumn{5}{|c|}{ Energy performance index } \\
\hline & $\begin{array}{l}\text { Working } \\
\text { days }\end{array}$ & $\begin{array}{l}\text { School } \\
\text { working days }\end{array}$ & $\begin{array}{l}\text { No School } \\
\text { working days }\end{array}$ & Saturday & $\begin{array}{l}\text { Sunday and } \\
\text { holidays }\end{array}$ & & $\begin{array}{l}\text { Working } \\
\text { days }\end{array}$ & $\begin{array}{l}\text { School } \\
\text { working days }\end{array}$ & $\begin{array}{l}\text { No school } \\
\text { working days }\end{array}$ & Saturday & $\begin{array}{l}\text { Sunday and } \\
\text { holidays }\end{array}$ \\
\hline Car & 20.0 & 19.8 & 20.5 & 20.0 & 23.4 & - & - & - & - & - & - \\
\hline Oil & 6.38 & 6.33 & 6.54 & 6.38 & 7.50 & 0.504 & 151.8 & 150.5 & 155.6 & 151.8 & 178.4 \\
\hline Diesel & 12.2 & 12.1 & 12.5 & 12.2 & 14.3 & 0.549 & 315.2 & 312.6 & 323.1 & 315.2 & 370.3 \\
\hline Electricity & 1.00 & 0.99 & 1.02 & 1.00 & 1.17 & 0.09 & 4.235 & 4.2 & 4.341 & 4.235 & 4.976 \\
\hline $\begin{array}{l}\text { Public } \\
\text { transport }\end{array}$ & 2.22 & 2.20 & 2.27 & 2.22 & 2.60 & 0.135 & 14.12 & 14 & 14.47 & 14.12 & 16,59 \\
\hline various & 0.28 & 0.27 & 0.28 & 0.28 & 0.33 & - & - & - & - & - & - \\
\hline Total & 42.00 & 41.65 & 43.05 & 42.00 & 49.35 & - & 485.3 & 481.3 & 497.5 & 485.3 & 570.3 \\
\hline
\end{tabular}


Table 4

Energy consumption by type of day according to the Smart attendance scenario.

\begin{tabular}{|c|c|c|c|c|c|}
\hline Energy (kWh) & Working days & School working days & No school working days & Saturday & Sunday and holidays \\
\hline 2030 & 392.9 & 277.2 & 46.5 & 25.2 & 31.8 \\
\hline 2050 & 82.3 & 58.1 & 9.7 & 5.3 & 6.7 \\
\hline
\end{tabular}

Table 5

Energy consumption according to the Carbon Creativity Scenario.

(i). EPI and consumption in2030 and 2050

\begin{tabular}{|c|c|c|c|c|c|}
\hline Energy (kWh) & Working days & School working days & No school working days & Saturday & Sunday and holidays \\
\hline 2030 & 2908.6 & 2263.5 & 379.5 & 205.4 & 259.3 \\
\hline 2050 & 1600.0 & 1128.8 & 189.3 & 102.4 & 129.3 \\
\hline
\end{tabular}

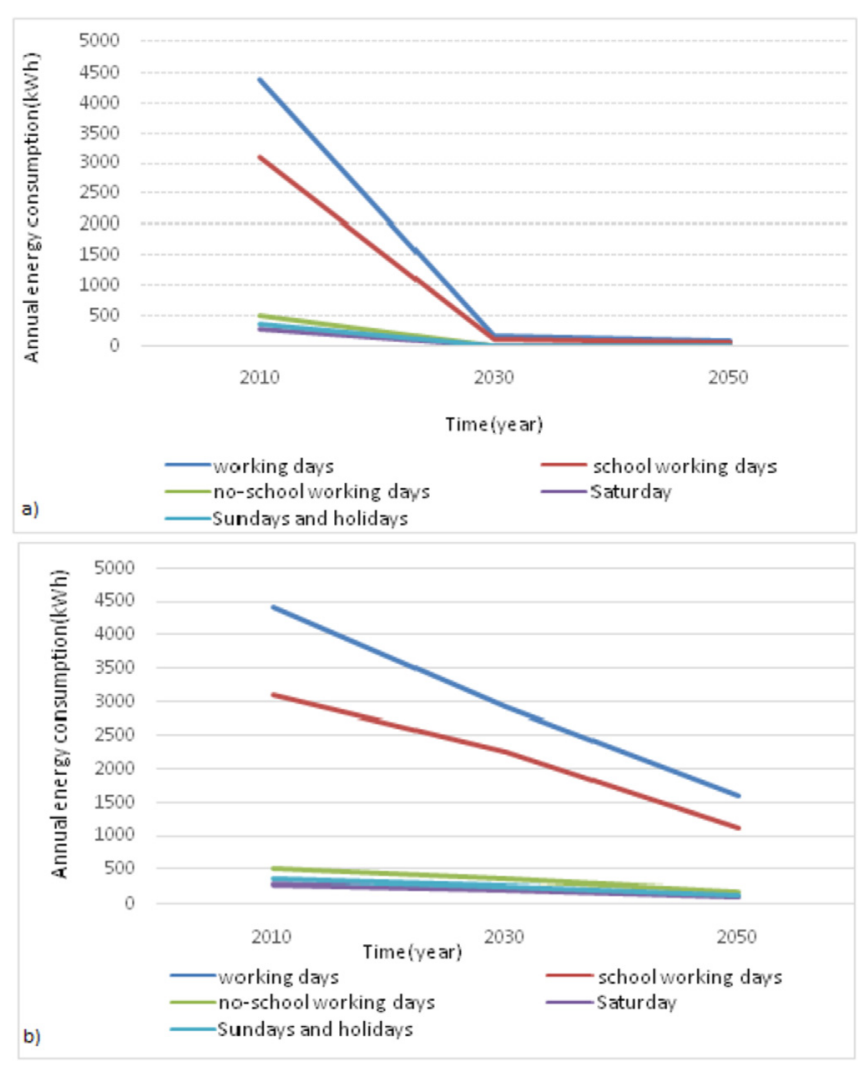

Fig. 6. Annual consumption by type of day, according to the Smart Attendance scenario (a), and Carbon Creativity scenario (b).

Because of the inequalities generated, of postponement of the weight of investments on future generations and its success conditioned by the possibility by French companies to take full advantage of the wave of innovation opened by a high carbon price, which, is far for Giving satisfaction, considering of the current economy state, this scenario is socially and politically unstable.

As hypothesis, such as in the previous scenario, we assume that the distances travelled by people have decreased, especially because of the economic crisis. On the other hand, we are witnessing the development of low-consumption technologies and the rise of electricity. We will assume that $10 \%$ of cars will be electric in 2030 and $40 \%$ in 2050. In parallel, the use of the car is reduced by $10 \%$ in 2030 and $40 \%$ in 2050 . Finally, consumption factors are reduced by $15 \%$.

The above hypotheses allow us to construct the Table 4. It was seen on Fig. 6b that annual energy consumption will vary during "the working days", between $2696 \mathrm{kWh}(2030)$ and $1483 \mathrm{kWh}(2050)$. During the "Sundays and holidays"the energy consumption is expected to be $240.3 \mathrm{kWh}$ (2030) and $119.8 \mathrm{kWh}(2050)$.

\subsubsection{New Climate and Energy Infrastructure (NCEI) scenario}

New Climate and Energy Infrastructure puts investment in cities at the energy heart and climate transition. As far as transport is concerned, the aim is to invest heavily in public transport infrastructure wherever it is profitable in the long term. The goal is to obtain in each city centre, the objective three thirds: a third of automobiles, a third of public transport and a third of soft modes (electric bike etc.). We are in a Saint Simonian perspective [36]. The construction of new infrastructures leads to accelerate the destruction of many dwellings, to consume a lot of resources and to increase the inequalities between the central and distant suburbs. The assumption is that this will be offset by future savings and a better quality of life is not assured.

However, in this scenario, more attention is paid to social aspects. It is still necessary that new public or private resources can be used to finance investments. We plan to invest massively in new public transport infrastructure alternatives to cars. From 2016, the economic situation is improving and the energy transition is in the foreground. In this scenario, the emphasis is largely on building, however, the urban renaissance also involves transportation. The projects of creation and extension of the networks will born during the decade 2025-2035.

This scenario, besides offering a massive investment strategy, carries the highest ambition for the modernization of cities. This is probably the most obvious path to the post-carbon city. However, there will be urban sprawl and uncontrolled localization dynamics, and below a certain density, public transport infrastructure cannot be made profitable. It also will risk create strong inequalities (see Table 5).

In this scenario, let us assume that the number of kilometres travelled per year is identical to that of 2010 , and that we will have a reduction of $10 \%$ in 2030 and $40 \%$ in 2050 of the car use to the benefit of the train/tram/metro, an additional the $5 \%$ of extra cars will be electric in 2030, and the 15\% in 2050 (see Table 6) (see Table 7).

Finally, the energy consumption of various factors of vehicle consumption will have decreased by $10 \%$ in 2030 and by $20 \%$ in 2050. Fig. 7a given some results of annual energy consumption according to this scenario.

\subsubsection{Biopolis scenario}

Biopolis offers a hybrid of nature, city and countryside [33]. It is the design of a new form of integration between the city and nature, which is more attractive for those who live there and 
Table 6

Energy consumption according to the New climatic and energy infrastructures.

\begin{tabular}{|c|c|c|c|c|c|}
\hline Energy (kWh) & Working days & School working days & No school working days & Saturday & Sunday and holidays \\
\hline 2030 & 3571.8 & 2520.0 & 422.5 & 228.7 & 288.6 \\
\hline 2050 & 1928.3 & 1360.5 & 228.1 & 123.5 & 155.8 \\
\hline
\end{tabular}

Table 7

Energy consumption according to the Biopolis scenario.

\begin{tabular}{|c|c|c|c|c|c|}
\hline Energy (kWh) & Working days & School working days & No school working days & Saturday & Sunday and holidays \\
\hline 2030 & 2597.5 & 2206.2 & 369.9 & 200.2 & 252.7 \\
\hline 2050 & 826.9 & 1044.9 & 175.2 & 94.8 & 119.7 \\
\hline
\end{tabular}

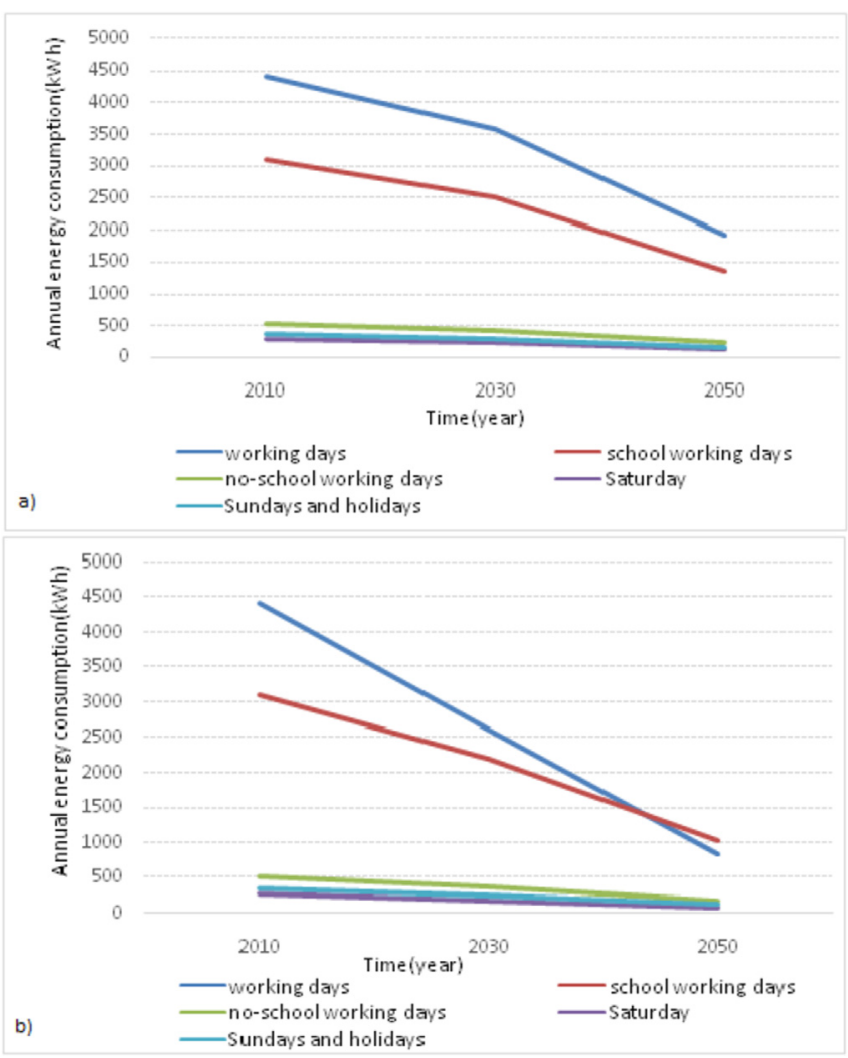

Fig. 7. Annual consumption by day type, New Climate and Energy Infrastructure (a) and, Biopolis (b) scenarios.

productive of more effective solutions to energy issues and climate risks. The notion that dominates is cycle. We favour the course circuits.

This scenario is the antithesis of the classic vision of the postcarbon city. The major event initiating and enabling this scenario is a strong energy decentralization for the benefit of local authorities.

From 2010, the trend of the natural emerges and there is a rejection of the mineral and the artificial. Three arguments are advanced: the equal mobility of urban and sub-urban dwellers, the choice of urbanity, and realism. We want to organize the sustainability of the extended city, the urban campaign, rather than densify the city.

From 2018, there is great political tension in the world, especially with the Middle East. In France, the trend is towards decentralization and priority is given to renewable energies. In 2025, an international agreement aimed at regional self-sufficiency is signed.
Given the low density, the individual vehicles remain very present, fueled for $20 \%$ by biofuels and for a smaller part by electricity. Over the 2040-2050 decade, with the development of local energy production, the rise of biochemistry, the importance given to the recovery of waste from biomass, and the use of recyclable materials. We have the basics of a circular economy. Let's assume that the number of kilometres travelled per person per year is the same as in 2010 and $20 \%$ of cars will be electric in 2030 and $60 \%$ in 2050 . Finally, the energy consumption of the various factors of vehicle consumption will have decreased by $15 \%$ in 2030 and 30\% in 2050 .

It was seen on Fig. $7 \mathrm{~b}$ that annual energy consumption will vary during "the working days", between 383.1 kWh (in 2030) and $826.9 \mathrm{kWh}$ (in 2050). During the "Sundays and holidays"the energy consumption is expected to be $37.27 \mathrm{kWh}$ (in 2030), and 119.7 $\mathrm{kWh}(2050)$.

\subsubsection{The continuous city}

Here, local authorities engage in policies of organization of their space and mobility, to relocate activities and housing to draw a denser, structured and accessible city.

This scenario strongly links local climate policy tools with those of planning. It seeks to control rents and land speculation. Finally, it introduces into the territorial taxation an explicit consideration of locations, which brings closer housing and employment and contains urban sprawl. The traffic in the city centre is limited, the near suburbs become the privileged places of strong density.

This scenario is only possible under three conditions: greater sensitivity to climate risks, institutional reforms and significant transfers to housing, land policies and public transport infrastructure.

Thanks to the compactness of the city, we can effectively reduce greenhouse gas emissions and oil consumption, especially in transport. However, the emphasis is on anticipation, therefore, in the long run, this scenario allows investment and operational savings.

As hypothesis, suppose that the number of kilometres travelled per year will be reduced by $10 \%$ in 2030 and by $20 \%$ in 2050 . For the modal shift, we use the modal split of 2010 of the Brussels Region instead of that of Wallonia. There is also a reduction of $10 \%$ in 2030 and $40 \%$ in 2050 from the use of the car to the benefit of the train/ tram/metro, 5\% of the cars will be electric in 2030 and $15 \%$ in 2050. Finally, an energy consumption the various factors of vehicle consumption will decrease by $10 \%$ in 2030 and by $20 \%$ in 2050 (see Table 8).

It was important to notice that during the "school working days", it was expected as consumption energy, $279.6 \mathrm{kWh}$, and $1065 \mathrm{kWh}$ in 2030 and 2050, respectively. Nevertheless, during the "No school working days", annual consumption energy will $46.87 \mathrm{kWh}$ by 2023 , and $178.5 \mathrm{kWh}$ by 2050 . Other results were showed on Fig. 8 a. 
Table 8

Energy consumption according to the continuous City scenario.

\begin{tabular}{|c|c|c|c|c|c|}
\hline Energy (kWh) & Working days & School working days & No school working days & Saturday & Sunday and holidays \\
\hline 2030 & 3007.9 & 1895.3 & 317.8 & 172.0 & 217.1 \\
\hline 2050 & 1508.9 & 1064.6 & 178.5 & 96.6 & 121.9 \\
\hline
\end{tabular}

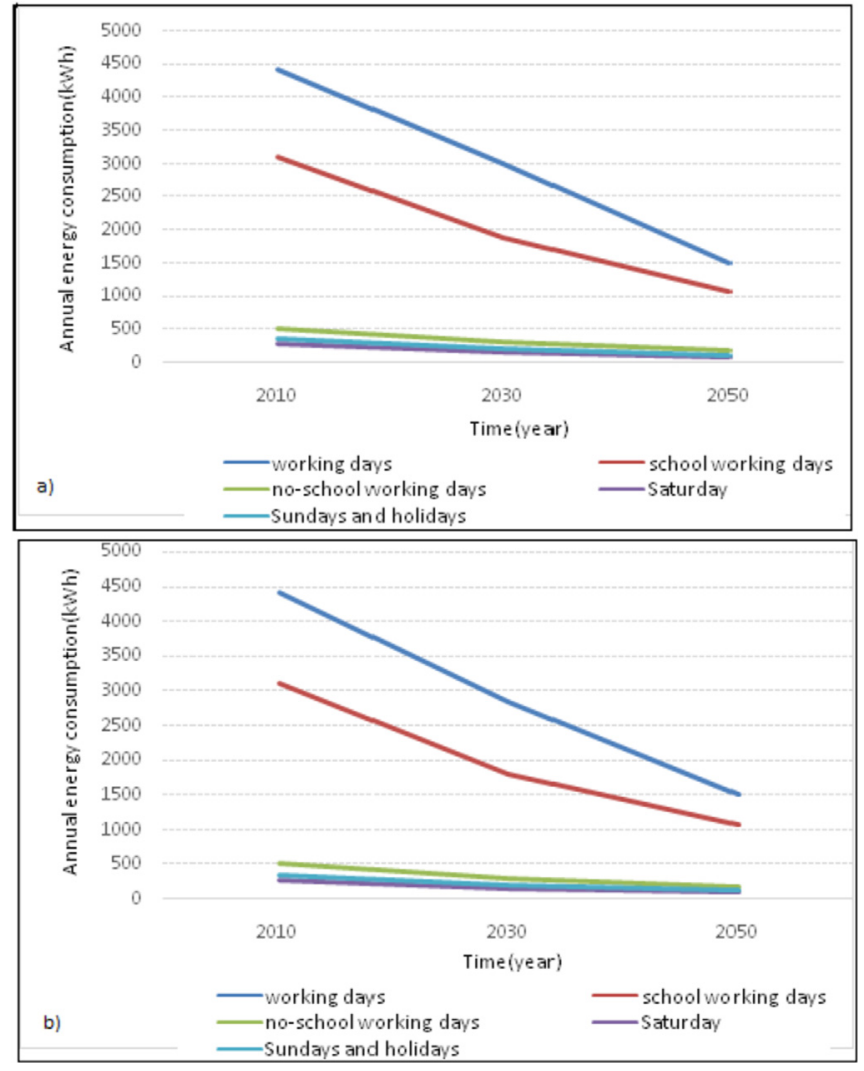

Fig. 8. Annual consumption by day type, continuous city (a), and sober urban (b).

\subsubsection{Urbanity sober}

This scenario is based on the belief that a major transformation to deal with the issues are and will be increasingly faced. We follow five tracks:

(i). The necessity: need to make face with the crisis and rising energy prices, save money and limit spending.

(ii). Incitement: efforts by public authorities and associations to promote more sober and virtuous consumption practices towards responsible consumption.

(iii). Private initiative: offers new products or services that are more robust and more economical, then new business models that respond to emerging demands.

(iv). The change in value: militant groups or a larger part of civil society, with more or less impact on all social groups and intermediate bodies. (v). Social and urban policy: committed to better take into account the social realities of the energy and climate crisis and to offer urban services or urban quality of life that can replace existing modes of market consumption.

Change is the result of all these initiatives. The scenario is structured around two phases: the beginnings of a decomposition of lifestyles and consumption and the development of new services and different forms of savings giving an important place to the local.

We assumed that the number of kilometres travelled per year is reduced by $15 \%$ in 2030 and by $30 \%$ in 2050 , based on the 2010 values. For the modal shift, we use the 2010 modal split of the Brussels instead of that of Wallonia. There is also a reduction of $10 \%$ in 2030 and $40 \%$ in 2050 from the use of the car to the benefit of the train/tram/metro, $5 \%$ of the cars will be electric in 2030 and $15 \%$ in 2050. Finally, an energy consumption different factors of vehicle consumption which will have decreased by $10 \%$ in 2030 and by $20 \%$ in 2050 (see Table 9).

It was interesting to notice on Fig. 8b, that, during the "working days", energy consumption will be 419 kWh by 2030, and 1509 kWh by 2050.

\section{Discussion}

Table 10 shows the synthesis of annual consumption by type of day, for the years 2010, 2030 and 2050.

All these scenarios have as foundation some hypothesis in majority taken in the literature [33-36]. The results showed that the trends were generally the same for all scenarios, regardless of the type of day. For the sake of clarity, we have taken consumption for an average working day, by scenario for the years 2010, 2030 and 2050. Analyzing Fig. 9, it is seen that only the passive and smart attendance scenarios, which, allowed achieve the lowest consumption levels in 2030, and in 2050. The "Passive attendance "is an improbable scenario in its implementation, because we start at the principle according to which, no political decision will be taken at any level.

On the other hand, the "intelligent attendance" scenario seems much more interesting in terms of data. But, if the objective is indeed to reduce them as much as possible, we must be careful: the context is as important as the reductions observed. Indeed, they are due to the biggest oil crisis ever encountered, and the economic and social context which was very catastrophic: the car was not more used as much because of the rise in the price of oil, or, travel needs are still Also present, the inhabitants of suburban areas turn to public transport, which remains a more economical solution. They are then overloaded [38]. The economic consequences of the oil price hike are also very serious: the price of real estate explodes in the city centre and collapses in the suburbs, as people seek to get

Table 9

Energy consumption according to the Urbanity sober scenario.

\begin{tabular}{|c|c|c|c|c|c|}
\hline Energy (kWh) & Working days & School working days & No school working days & Saturday & Sunday and holidays \\
\hline 2030 & 2840.8 & 1790.0 & 300.1 & 162.5 & 205.0 \\
\hline 2050 & 1508.9 & 1064.6 & 178.5 & 96.6 & 121.9 \\
\hline
\end{tabular}


Table 10

Summary of energy consumption by type of day.

\begin{tabular}{|c|c|c|c|c|c|c|}
\hline & & Working days & School working days & No school working days & Saturday & Sunday and holidays \\
\hline 2010 & & 4408.7 & 3110.5 & 521.6 & 282.3 & 356.3 \\
\hline \multirow[t]{7}{*}{2030} & Passive Attendance & 4493.0 & 3170.0 & 531.6 & 287.7 & 363.1 \\
\hline & Smart attendance & 392.9 & 277.2 & 46.5 & 25.2 & 31.8 \\
\hline & Carbon creativity & 2908.6 & 2263.5 & 379.5 & 205.4 & 259.3 \\
\hline & New climatic and energy infrastructures & 3571.8 & 2520.0 & 422.5 & 228.7 & 288.6 \\
\hline & Biopolis & 2597.5 & 2206.2 & 369.9 & 200.2 & 252.7 \\
\hline & Continuous City & 3007.9 & 1895.3 & 317.8 & 172.0 & 217.1 \\
\hline & Urbanity sober & 2840.8 & 1790.0 & 300.1 & 162.5 & 205.0 \\
\hline \multirow[t]{7}{*}{2050} & Passive Attendance & 4989.0 & 3520.0 & 590.2 & 319.5 & 403.2 \\
\hline & Smart attendance & 82.3 & 58.1 & 9.7 & 5.3 & 6.7 \\
\hline & Carbon creativity & 1600.0 & 1128.8 & 189.3 & 102.4 & 129.3 \\
\hline & New climatic and energy infrastructures & 1928.3 & 1360.5 & 228.1 & 123.5 & 155.8 \\
\hline & Biopolis & 826.9 & 1044.9 & 175.2 & 94.8 & 119.7 \\
\hline & Continuous City & 1508.9 & 1064.6 & 178.5 & 96.6 & 121.9 \\
\hline & Urbanity sober & 1508.9 & 1064.6 & 178.5 & 96.6 & 121.9 \\
\hline
\end{tabular}

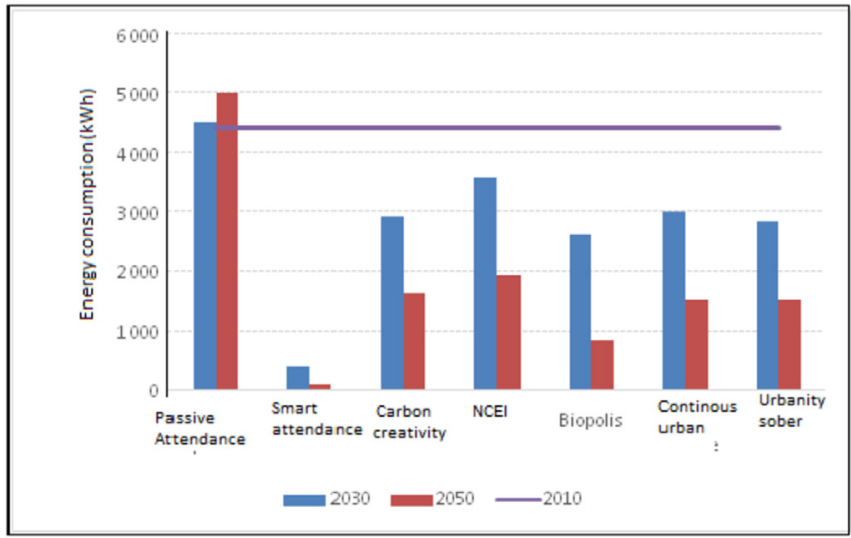

Fig. 9. Consumption for one working day per scenario.

closer to their workplaces, to reduce their travel bills. Besides, if commuting is necessary, households will cut their home-leisure expenses, which will also have negative consequences for the economy. Summary, the need for travel (and therefore of the car) is still strong, but it becomes complicated for a large part of households to afford this expense. In this scenario, we sacrifice the social and the economy for the ecology: it is not a durable solution. As for the other scenarios, they all have in common the creation of social inequalities. It seems like an inevitable eventuality. However, some scenarios seem less acceptable to us than others. Carbon creativity means relying on future generations to partially get rid of the weight of investments. This is what we want to avoid at all costs. The aim is to improve the situation for the future, to provide a lasting solution and not to postpone the problem. One creates social and political instability, once again in favour of the ecology: it is not a durable solution. The scenario "Biopolis", meanwhile, does not dissociate enough from the use of the car, and oil. The low density of cities means that it is difficult to make public transport profitable, and the car is still very present.

The most interesting scenarios are "New Climate and Energy Infrastructure", "Continuous City", and "Urbanity sober". These three scenarios focus on anticipation and strong investment. Their prerequisites are important and have strong consequences, especially on the economy [42-46]. These findings asserted the results found by Marique and Reiter [37] who showed that the sustainable energy is more adapted in Continuous Cities. We think in the long term, and it seems that these scenarios are the most viable. The study of these scenarios makes it possible to show the need to act, and to think of long-term solutions. However, we realize that the most sustainable scenarios require very strong political decisions and a social acceptance that is far from being obvious in the current context. The challenge is to work in the long term but are households willing to make sacrifices for future generations, nothing is really safe. But to make these households understand that delaying the problem will only worsen it (in the manner of the "Smart attendance" scenario, which is in continuity with the functioning of current policy), is an absolute necessity. Objectively, we can rely on the consumptions of "New Climate and Energy Infrastructure", "Continuous City" and "Urbanity sober", which will allow to have a range of possible values. The use of the bike for transport within $12 \mathrm{~km}$, and the bus as public transport will significantly reduce the energy consumption of the transport sector. Indeed, in 2004, Cameron et al. [40] showed that the vehicle consumes about twice as much energy per passenger-km than a bus and almost ten times more than train. It is seen in Fig. 10, that rich cities such as Hamburg and Brussels, poor cities, such as Seville, north city (Stockholm), southern Europe city (Lisbon), and populated city (Madrid), have different energy consumptions. Indeed, the energy consumption due to transport, per capita, is all greater as a city is considered rich. The energy consumption in the city of Liege is slightly below the average of the 34 cities represented [41]. This means that although this city is not very populated, the energy used in mobility is enormous.

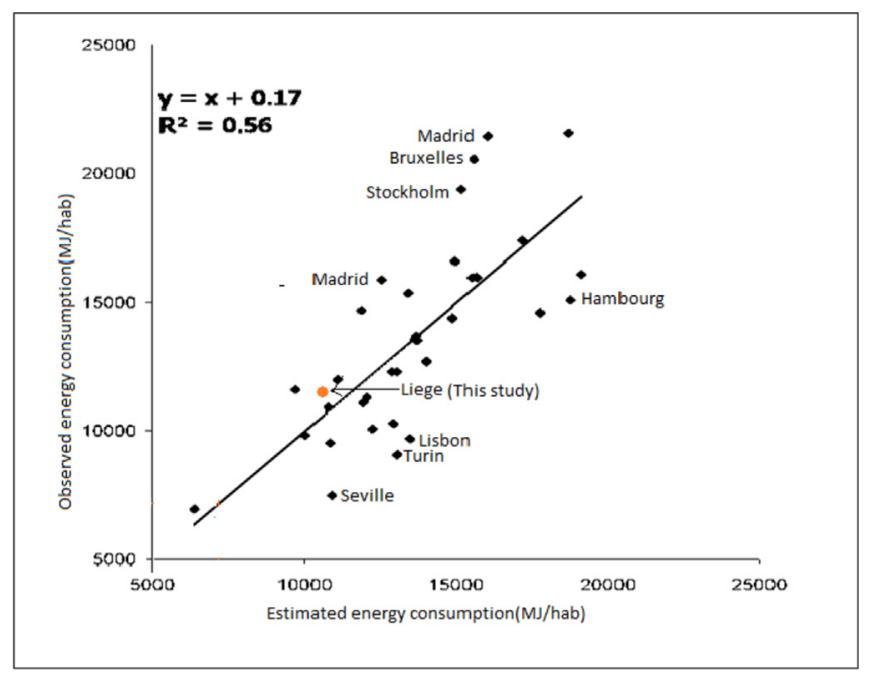

Fig. 10. Comparison of energy consumption due to transport by inhabitant in nine cities [41]. 


\section{Conclusion}

This research sets up an energy performance index based on the movements of Liege residents according to the type of day for the years 2010, 2030 and 2050. These scenarios, even if some are very utopian, allow to have a precise idea of the sometimes tragic consequences that certain political actions (or non-actions) may have. It is necessary to act in the long term by investing a lot in cities and transport. This work also shows how important the mode of transport is in a city and how serious the consequences can be if they become dysfunctional (explosion of the price of real estate, deterioration of living conditions, decrease in purchasing power ...). It is possible to limit oil and other fossil fuel vehicles with the aim of preserving the environment and designing sustainable cities by 2030 . This work proposes scenarios that can facilitate this vision of the future. In all the scenarios it is noticed that energy consumption due to transportation is the highest during the working days and the lowest on Saturday.

This research opens the door to a deeper evaluation of the energy consumed in urban transport, reducing the time scale, while trying to maintain the results on a daily basis, which will allow the use of meteorological data., and include a new parameter, but also space. In spite of this, like any other research, this work has limits, in fact, it focuses only on the aspect "energy and transport in the cities. It is important to evaluate in future research, the consumption of energy in the different types of building in this city.

\section{Acknowledgment}

The authors acknowledge the AXA Company for their support in this work, and the LEMA laboratory team of university of Liege, which have conducted this study.

\section{References}

[1] Nematchoua Modeste Kameni, Tchinda René, Noël Djongyang, Ricciardi Paola. A field study on thermal comfort in naturally-ventilated buildings located in the equatorial climatic region of Cameroon. Renew Sustain Energy Rev 2014;39:381-93.

[2] Nematchoua Modeste Kameni, Tchinda René, José A. Orosa. Thermal comfort and energy consumption in modern versus traditional buildings in Cameroon: a questionnaire-based statistical study. Appl Energy 2014;114:687-99.

[3] Nematchoua Modeste Kameni, Ricciardi Paola, Buratti Cinzia. Statistical analysis of some complex parameters coming from the subjective responses of building occupants in a tropical region of the Madagascar island. Appl Energy 2017;208:1562-75.

[4] Siddiqi A, Anadon LD. The water energy nexus in Middle East and North Africa Energy Policy 2011;39(8):452-94.

[5] Aissaoui A. MENA energy investment outlook: capturing the full scope and scale of the power sector. 2012. No 10. [Online], Available at:vol. 7, http:/ www.apic.com/Research/Commentaries/Commentary_V07_N10_Oct2012. pdf. [Accessed 21 July 2013].

[6] K Hussey Pittock J. The energy and water nexus: managing the links between Energy and water for a sustainable future. Ecol Soc 2012;17(1):31.

[7] IPCC. Climate change 2007: synthesis Report.Contribution of working groups I II and III to the fourth assessment report of the intergovernmental panel on climate change. Cambridge, UK: Cambridge University Press; 2007.

[8] Wang C, Cai W, Lu X, Chen J. $\mathrm{CO}_{2}$ mitigation scenarios in Chinas Road transport sector. Energy Convers Manag 2007;48:2110-8.

[9] Yan X, Crookes RJ. Reduction potentials of energy demand and GHG Emissions in China's road transport sector. Energy Policy 2009;37:658-68.

[10] IEA. Golden rules for a golden age of gas. 2012. Accessed Dec 2015, www.iea org/publications/freepublications/publication/WEO2012_GoldenRulesReport.

[11] Foley Aoife, Tyther Barry, Calnan Patrick, Gallachóir Brian Ó. Impacts of Electric Vehicle charging under electricity market operations. Appl Energy 2013;101:93-102.

[12] International Energy Agency (IEA). World energy outlook. Paris, France: IEAand Organisation for Economic Co-operation and Development(OECD) 2008

[13] Hao H, Wang H. YiR.Hybrid modelling of China's vehicle ownership and projection through 2050. Energy 2010;36:1351-61.

[14] Belgium: Indicators for 2015, Agence internationale de l'énergie. http://www. iea.org/statistics/statisticssearch/report/? year $=2015 \&$ country $=$ BELGIUM $\&$ product $=$ Indicators .
[15] Un nouveau protocole de mesure de consommation de carburant en conditions réelles[archive] sur fne.asso.fr, site de France Nature Environnement.

[16] Chancel LL. énergiegrise: la face cachée de nosconsommationsd'énergie. Institut du développement durable et des relations internationales; 2013.

[17] Comment les émissions de gaz à effet de serreévoluent-elleactuellement?.Ssur manicore.com, site web de Jean-Marc Jancovici.

[18] Allaire J. Choisir son mode de ville: formesurbaineset transports dans les villes émergentes. Cahiers de global chance; 2006. p. 66-70.

[19] Barter P. An international comparative perspective on urban transport and urban form in pacific asia: the challenge of rapid motorisationin dense cities, ph.D. Thesis. Murdoch University; 1999.

[20] Allaire, J. Une forte responsabilité du secteur des transports dans la criseclimatique. http://www codatu.org/actualites/une-forte-responsabilite-dusecteur-des-transports-dans-la-crise-climatique/.

[21] IEA. A policy guide on how to transform cities by improving energy efficiency in urban transport systems. A Tale of Renewed Cities. http://www.iea.org/ publications/freepublications/publication/renewed_cities_web.pdf.

[22] Poudenx P. The effect of transportation policies on energy consumption and Greenhouse gas emission from urban passenger transportation. Transport Res Pol Pract 2008;42:901-9.

[23] Ogilvie D, Egan M, Hamilton V, Petticrew M. Promoting walking and cycling as an alternative to using cars: systematic review. BMJ 2004;329:763 (Clinical researched.).

[24] Fujii S, Garling T, Kitamura R. Changes in drivers' perceptions and use of public transport during a free way closure effects of temporary structural Change on cooperation in a real-life social dilemma. Environ Behav 2001;33: 796-808.

[25] Cairns S, Sloman L, Newson C, Anable J, Kirkbride A, Goodwin P. Smarter choices-changing the way we travel.Technical Report. UCL UniversityCollege London, Department for Transport; 2004.

[26] Parker J, Wilkinson J, Chatterjee K, Barrett D, Harris J. Making persona ltravel planning work. Technical Report. Department for Transport UK; 2007.

[27] BVI. Transport in figures.Technical report. Germany: BundesministeriumfrVerkehr Und digitaleInfrastruktur; 2002.

[28] CambridgeSystematics Inc. Moving cooler: transport strategies to reduce greenhouse gas emissions. Technical report. Washington, DC: Urban Land Institute; 2009.

[29] Garvill J, Marell A, Nordlund A. Effects of increased a wareness on Choice of travel mode. Transportation 2003;30:63-79.

[30] Eric Cornelis, Michel Hubert, Philippe Huynen, Kevin Lebrun, Geoffroy Patriarche, Astrid De witte, Lieve Creemers, Katrien Declercq, Davy Janssens, Marie Castaigne, Laurie Hollaert, Fabien Walle. La MobilitéenBelgiqueen 2010: Résultat de l'enqueteBELDAM.PoliticScientifiquefederale.

[31] ICEDD asblpour le compte du Service Public de Wallonie. Bilanenergetique de la walloniebilanprovisoire 2013. ctobre 2014;3(52).

[32] Bogaert Henri. Perspectives énergétiquespour la Belgiqueà l'horizon 2030. Analyses etprévisionséconomiques Bureau fédéral du Plan Novembre 2011;10(165).

[33] Jacques Theys, Éric Vidalenc. Repenser les villes dans la société post-carbone. ADEME; 2013. p. 305. enligne: http://www.developpement-durable.gouv.fr/ Repenser-les-villes-dans-la.html.

[34] Statbel. Population par province et par âge, au 1er janvier 2016-2061. Belgian Federal Government, enligne; 2013. http://statbel.fgov.be/fr/modules/ publications/statistiques/population/downloads/population_au_1er_janvier_ 2016-2061.jsp.

[35] En ligne. Evolution du prix du baril de pétrole depuis 1990. 2013. 13 novembre, http://prixdubaril.com/comprendre-petrole-cours-industrie/3892prix-du-petrole-brut-brent-depuis-1990.html [Cours du baril].

[36] Doctrine économique et sociale qui préconise l'association, l'amélioration du sort des plus nombreux, l'effacement du politique au profit de l'économie. [Source: CNRTL)]

[37] Anne-Françoise Marique, REITER Sigrid. A Method to evaluate the energy consumption of suburban neighborhoods. HVAC R Res 2012;18(1-2):88-9.

[38] Sigrid Reiter, Anne-Françoise Marique. Towards low energy cities: a case study of the urban area of Liège. J Ind Ecol 2012;16(6):829-38.

[39] Commission of the European Communities. Communication from the commission to the European parliament, the council, the European economic and social committee and the committee of the regions. 2020 by 2020 Europe's climate change opportunity, vol. 30. COM; 2008. final; 2008.

[40] Cameron I, Lyons T, Kenworthy J. Trends in vehicle-kilometers of travel in world cities, 1960-1990: underlying drivers and policy responses. Transport Pol 2004:287-98.

[41] Florent LeNéchet. Consommationd'énergieetmobilitéquotidienneselon la configuration des densitésdans 34 villeseuropéennes. URL: http://journals. Open.edition.org/cybergeo/23634.

[42] Nematchoua Modeste Kameni, Yvon Andrianaharison, Kalameu Omer Asadi Somayeh, Choudhary Ruchi, Reiter Sigrid. Impact of climate change on demands for heating and cooling energy in hospitals. An in-depth case study of six islands located in the Indian Ocean region. Sustain Cities Soc 2019;44: 629-45.

[43] Nematchoua Modeste Kameni, Ricciardi Paola, Reiter Sigrid, AndrianaharisonYvon. A comparative study on optimum insulation thickness of walls and energy savings in Equatorial and Tropical climate. Int J Sci Build Environ 2017: $1-13$.

[44] Nematchoua Modeste Kameni, Ricciardi Paola, Buratti Cinzia. Thermal 
comfort and comparison of some parameters coming from hospitals and shopping centers under natural ventilation; A Case of Madagascar island. J Build Eng 2017;13:196-206.

[45] Nematchoua Modeste Kameni, Ricciardi Paola, Buratti Cinzia. Adaptive approach of thermal comfort and correlation between experimental data and mathematical model in some Schools and traditional buildings of Madagascar under natural ventilation. Sustain Cities Soc 2017:31030-2. S2210-6707.

[46] Nematchoua Modeste Kameni, Ricciardi Paola, Orosa José, Buratti Cinzia. A detailed study of climate change and some vulnerabilities in Indian Ocean:A case of Madagascar island. Sustain Cities Soc 2018;41:886-98. 